\title{
Education, English Language Proficiency, And Earnings Of Male Immigrants In The U.S. Labor Market
}

Jongsung Kim, (E-mail: jkim@bryant.edu), Bryant College

\begin{abstract}
Using samples of male Mexican and Chinese immigrants taken from 1990 Census PUMS data, this paper investigates the determinants of English language proficiency (ELP) and its effect on male immigrants' earnings. The findings are: 1) the educational attainments are crucial in improving ELP; 2) the effects of ELP on earnings are significant for both Chinese and Mexican immigrants and among all educational categories. The importance of educational attainment and ELP on the immigrants' economic success is reestablished.
\end{abstract}

\section{Introduction}

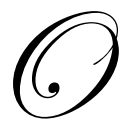

ver the last three decades, the proportion of foreign-born population, or immigrants, in the U.S. increased from 4.7 percent in 1970 to 11.1 percent in 2000. This is the highest record since 1930, when 11.6 percent of the population was foreign-born. The 31.1 million immigrants reported in the Census 2000 represent a 57 percent increase over the 1990s, which exceeds 40 percent in 1980s and 47 percent in 1970s. Steady influx of immigrants has been raising concerns among the natives on many issues. Some worry that the immigrants will crowd out the labor market, and influence the native workers' wage adversely. Immigrants are also viewed as burdensome since they are believed to take from the collective pot by taking advantage of relatively generous American welfare system without contributing correspondingly. Since the economic assimilation of immigrants, characterized by earnings parity with the natives, determines whether or not immigrants are beneficial to the U.S. economy, the question of economic assimilation of immigrants has received a great deal of research attention.

Most of immigrants arrive in the U.S. with skills of limited use in the U.S. labor market, facing an initial earnings disadvantage (Chiswick, 1978). With the passage of time, immigrants transform country of origin specific human capital into the skills that are valued in the U.S. labor market. Although it is still true that some immigrants overcome obstacles and attain socioeconomic parity with the U.S. natives, the simple linear assimilation theory has received a close scrutiny as the national origin of immigrants has changed. ${ }^{1}$ Economic assimilation of immigrants is important for at least two reasons. First, immigrants' economic assimilation not only generates higher tax revenue, but also reduces the probability of immigrants' tapping into welfare benefits. Second, from the perspective of intergenerational mobility, as immigrants fare better, their economic success will trickle down to future generations, by investing more in their children to lay out the groundwork for the socioeconomic success in the future.

Human capital theory stipulates that individual earnings are determined by the human capital endowments, educational attainment probably being the most important. For immigrants, equally important human capital is the English language proficiency (hereafter ELP). Communication skill is an integral part of work. Without proper ELP, educational attainment accumulated in the country of origin fails to be adequately translated into earnings power in the U.S. labor market. ELP is also important for immigrants' social integration in addition to their economic assimilation. ${ }^{2}$ Naturally, the increasing influx of immigrants is associated with an increase in the number of people whose native language is not English. Even after residing in the U.S. for a while, many immigrants use their native languages at home. It was reported that the number of people 5 years old and over in the U.S. who spoke a

Readers with comments or questions are encouraged to contact the author via email. 
language other than English at home increased by 48 percent over 1990s: 47.0 million in 2000, up from 31.8 million in 1990. Of these, 21.3 million spoke English less than "very well," up from 14.0 million in $1990{ }^{3}$

This paper, using 1990 Census Public Use Microdata Sample (PUMS), investigates the determinants of ELP and how ELP influences the male immigrants' earnings, focusing on two major immigrant sending countries: Mexico and China. According to Mosisa (2002), Mexico and China rank first and fourth place in the category of foreign-born population, with the Philippines and India being second and third. The economic impact of immigrants on the U.S. economy heavily depends on the nature of immigrants from these countries. Focusing on Mexican immigrants is advantageous since they are the largest and most visible immigrant group in the U.S. (Espinosa and Massey, 1997). The Philippines and India were excluded in this study because 1) English language is used widely in both countries in comparison with China, therefore the impact of ELS on the economic status of the immigrants from the Philippines and India may be less clear and 2) given the size of population body, the number of Chinese immigrants is likely to surpass the number of immigrants from the Philippines and India, reaching at the second place in the near future. ${ }^{4}$

\section{Related studies}

While a number of studies have looked at the effects of time spent in the U.S. on the earnings of immigrants, the effect of language ability has been examined much less thoroughly, perhaps due to the lack of scientific measures of language abilities in data sets sufficiently large enough to be used for immigration studies (Bellante and Kogut, 1998). Economists conventionally view the ELP as a form of human capital specific to the U.S. labor market, and that limited ELP leads to lower earnings (McManus, 1985). Communication barriers as a result of the lack of ELP may cause other problems as well: lower academic performance of foreign-born children, ineffective delivery of health service and even unfair treatment in legal system, including police brutality (Espenshade and Fu, 1997).

Relationship between immigrants' ELP and the labor market outcome has received a considerable research attention. Dávila and Mora (2001) investigated factors related to ELP, as well as the impact of ELP on the earnings distributions among major Hispanic populations in the U.S. They, using synthetic cohorts data in the 1980 and 1990 U.S. Census PUMS, found that Mexican-Americans and other Hispanics acquired English fluency at a faster pace than Puerto Ricans and Cuban-Americans during the 1980s. Their results also suggest that English-skill investment differently influenced the earnings distributions of these ethnic groups.

The impact of ELP on earnings has been analyzed for other English-speaking environments. Dustman and Fabbri (2000), using two recent U.K. surveys, showed that language acquisition, employment probabilities, as well as earnings differ widely across non-white immigrants, according to the ethnic origin. It was found that language has a strong and positive effect on employment probabilities. Furthermore, lack of English fluency leads to a substantial earnings loss for immigrants. While earnings of white and ethnic minority natives develop in a similar manner, there is a large earnings gap between these two groups, and ethnic minority immigrants. English fluency contributed considerably to reduce these differences.

As immigrants tend to reside together at least in the initial stage of settlement, research attention has been focused on the association of ethnic enclave and the acquisition of ELP. ${ }^{5}$ As Gonzalez (2000) indicated, workers living in ethnic enclaves tend to encounter less incentive to acquire ELP because most communications and activities are conducted in their own languages. Lazear (1995) developed a model to show that the probability of acquiring the language used in the host country increases as the relative size of the minority population decreases. The empirical implication of this finding is that immigrants who reside in the ethnic enclaves should have lower ELP. One conjecture is that those who have limited knowledge in English tend to reside in ethnic enclave where the use of English is minimized to avoid the labor market penalty on their inability to communicate well in English. Focusing on this notion, McManus (1989) adds to this evidence by investigating the relationship between the residence in the ethnic enclave and earnings. His empirical results are consistent with theoretical predictions: enclaves do reduce the earnings losses associated with limited English skills for Hispanic men. Regardless of the human capital endowments, immigrants without ELP will not be able to find good jobs, as employers shy away from employing them 
since they are less useful to the business. Workers without proper ELP become even less useful over times as new technologies develop and economies of scale emerge.

This interpretation follows mainly from viewing language as human capital as the ability to speak English may have an effect on productivity. Ability to speak English is also necessary in order to get information about jobs. Speaking fluency may largely be acquired by exposure to the host country language, while writing and reading in a foreign language is a skill which is more difficult to obtain. Acquisition requires a more systematic way of learning, and the general level of schooling obtained may enhance the efficiency of acquiring this component of language capital. Dustmann and Fabbri (2000) substantiated this notion by showing that educational background variables have larger coefficients for reading and writing skills. Having considered the various roles of ELP on the immigrants' labor status, this paper examines the following empirical implications.

1. ELP and the time of arrival. Language acquisition depends not only on the length of learning periods but also, probably more importantly, on "when to start." According to "Critical Period Hypothesis," youths learn languages more easily than adults. This notion, applied to immigrants to the U.S., predicts that those who arrive at an earlier age will develop better ELP than those who arrive at a later age (Bleakly and Chin, 2002).

2. ELP and earnings. Human capital theory views that language ability influences the productivity. Therefore, immigrants with better ELP should, ceteris paribus, receive higher earnings than those without it. ELP is believed to produce different effects on earnings across different groups of immigrants.

3. ELP and education. Since investment in schooling provides externalities and highly educated individuals tend to be more productive when working with other well-educated people than alone (Little and Triest, 2002), the returns to education should be lower for the worker who suffer from a language handicap. The penalty of not having proper ELP should be greater for better-educated workers whose works usually require good communication skills.

\section{Data and empirical results}

This paper uses the 1990 Census 5 percent PUMS which provides sufficiently large samples for foreignborn populations. The sample consists of non-student full-time male workers between the ages 25 and 64 who were born either in Mexico or in China and reside in the U.S. ${ }^{6}$ We focus on workers because the incentives to acquire ELP should be strongest among those committed to labor market activity (Dávila and Mora, 2001). The sample is restricted to men because women's labor force participation behavior is known to be different from that of men. ${ }^{7}$ In order to minimize the impact from outliers, individuals in the top and bottom one percent in the earnings distribution were excluded. Table 1 explains the variables to be used and lists sample statistics.

Table 1 clearly shows that Chinese and Mexican immigrants are quite different in demographic and socioeconomic characteristics. Chinese immigrants are better educated; have more experiences in the labor market; have better ELP, and earn more than Mexican immigrants. Chinese immigrants are also more likely to be married, and less likely to reside in the South. The length of residency in the U.S. is the only area in which no discernible disparity exists.

In line with previous works, this paper uses a semilog specification with the logarithmic transformation of hourly wage being the dependent variable in the earnings estimation. One advantage of the use of the semilog model is the straightforward interpretation of the estimated coefficients of explanatory variables. The estimated coefficient of an explanatory variable is interpreted as the percentage change in earnings given a change in the explanatory variable. The dependent variable LnWage in the earnings estimation is obtained by dividing the annual earnings that includes wages or salary income earned in 1989 by the number of hours worked, which is the product of the number of weeks worked and the hours usually worked in a week. This is an appropriate variable since the focus of this paper is directed to the question of how the ELP rewards workers in the labor market. 
The variable "Experience" approximates the number of years since the individual left school, and is thus defined as "Age - Years of Schooling - 6," and to avoid an infinitesimal value of estimates, "Experience Squared" is imputed by dividing the square of experience by 100. Since the Census provides the educational attainment only by categories, excluding $9^{\text {th }}, 10^{\text {th }}$, and $11^{\text {th }}$ grade, this paper imputes the years of schooling using the midpoints of each category.

Census PUMS contains information on self-reported ELP based on the question "How well does this individual speak English?", The responses consist of "Only English is spoken at home," "very well," "well," "not well," and "not at all." "Only English is spoken at home," and "Very well" categories are combined to indicate the highest ELP. Included in the data analysis are 4 mutually exclusive dichotomous dummy variables for ELP, which can provide more precise results than the use of one dichotomous variable.

Table 1: Explanation of the variables and sample statistics

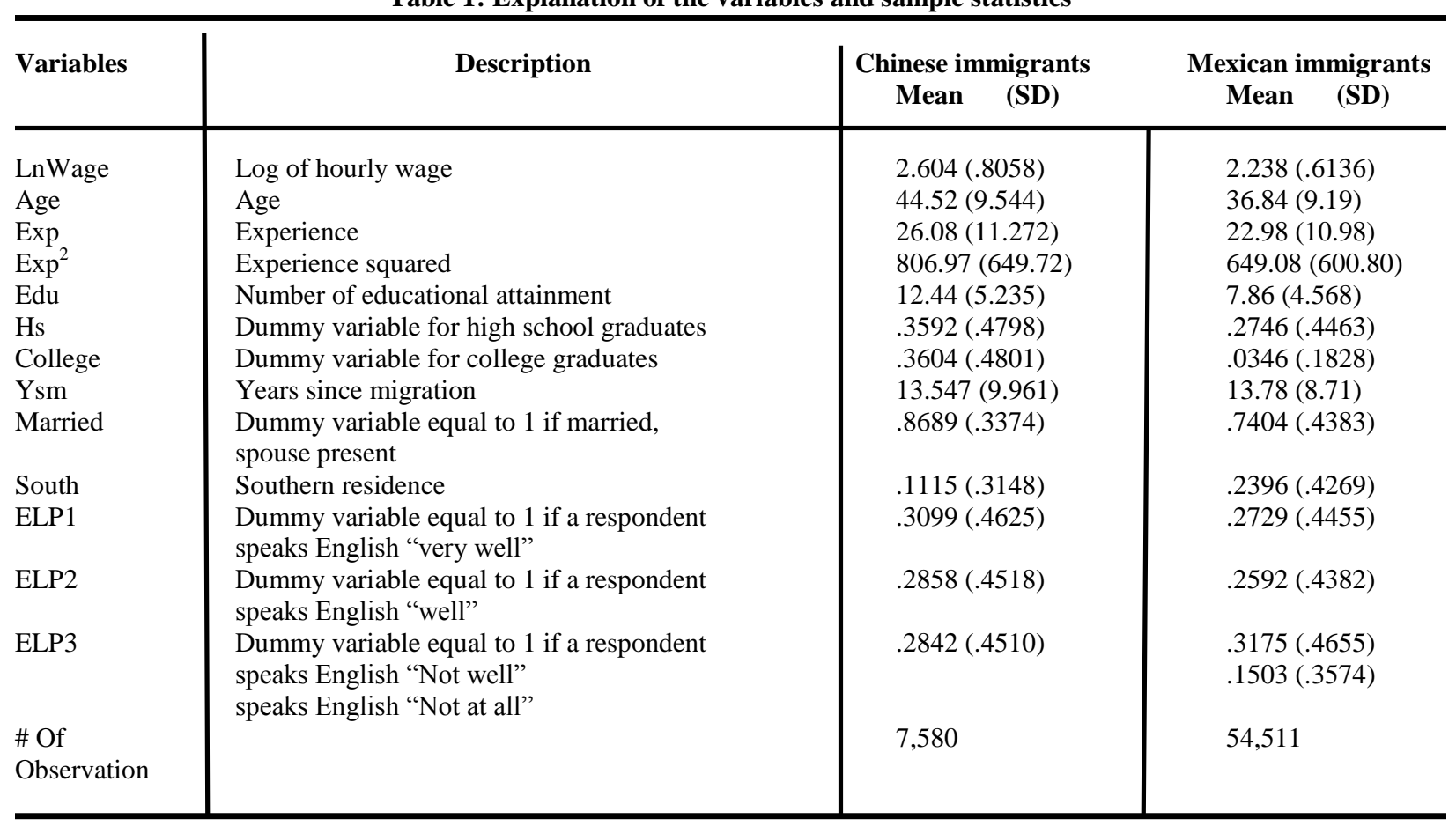

Year of arrival to the U.S. is reported in multi-year intervals, with more detailed interval for the recent past. Following Bellante and Kogut (1998), we approximated year of entry by using the mid-point of the indicated bracket, except for the pre-1950 bracket. For this bracket, the assumed year of entry was 1948 . Since less than 1 percent of immigrants in the samples came to the U.S. before 1950, the empirical results should not be sensitive to the particular choice of assumed year of entry for this bracket.

We first investigate factors influencing the acquisition of ELP and then analyze the effects of ELP on the earnings. Since the acquisition of ELP is a costly endeavor rewarded in the labor market (Gonzalez, 2002), it is instructive to identify the variables that would influence ELP. To do this, we estimate ordered probit model that regress ELP on a vector of socioeconomic variables related to the acquisition of ELP (Chiswick and Miller, 1995). The vector includes age at arrival (and square), labor market experience, years since migration, educational attainment, and the state of residence. Following empirical specification will be estimated.

(1) $E L P=f($ age at arrival, years since migration, experience, education, location of residence) 
The dependent variable ELP measures the English language proficiency as explained in the Table $1 .{ }^{9} \quad$ Variables that are expected to influence the ELP are grouped into three categories: human capital endowments, demographic characteristics, and the location of residence. Age at migration has been recognized as an important factor influencing subsequent ELP (Grenier, 1984). Immigrants arrived in the U.S. at a younger age would have more economic incentives to invest in learning English since they can expect higher earnings over the longer life cycle (Espenshade and Fu, 1997). The acquisition of ELP may, in addition, depend on the extent to which individuals are exposed to the language of the majority population. A variable that measures exposure is the time of residence in the U.S. It is also likely that the acquisition pattern of ELP differs across locations of residence as the relative size of the ethnic minority population to which the immigrant belongs. Two location variables "California," and "Texas," will account for the impact of workers' residence in the heavily immigrants populated states on the ELP.

Estimated results reported in Table 2 generally confirm the theoretical expectations. A positive (negative) regression coefficient means that an increase in the value of the explanatory variable is expected to increase (decrease) a respondent's ELP. For both Chinese and Mexican immigrants, the negative sign of the estimated coefficient of the variable "Experience" implies that older experienced workers are less likely to be proficient in English language. Positive signs for the estimated coefficients for the variable "Yearns since migration," "High school," and "College," confirms the theoretical predictions that the length of residence in the U.S. and higher educational attainment will help workers to acquire ELP.

Table 2: Ordered Probit Results for the determinants of ELP

\begin{tabular}{l|c|c}
\hline Variable & Chinese immigrants & Mexican immigrants \\
\hline Age at arrival & $.0349^{*}(.0086)$ & $-.0074^{*}(.0029)$ \\
Age at arrival squared /100 & $.0076(.0091)$ & $.0681^{*}(.0039)$ \\
Experience & $-.0703^{*}(.0059)$ & $-.0553^{*}(.0017)$ \\
Years since migration & $.0988^{*}(.0062)$ & $.0855^{*}(.0019)$ \\
High school & $.3961^{*}(.0530)$ & $.3175^{*}(.0163)$ \\
College & $1.101^{*}(.0769)$ & $.6427^{*}(.0365)$ \\
California & $.0292(.0272)$ & $-.1929^{*}(.0118)$ \\
Texas & $.2769^{*}(.0881)$ & $-.1587^{*}(.0145)$ \\
Adjusted $\mathrm{R}^{2}$ & .2460 & .1178 \\
\# Of observation & 7,580 & 54,511 \\
\hline
\end{tabular}

* Statistically significant at 5 percent level

The empirical evidence for the "Age at arrival" and "Location of residence" offers mixed results. For Mexican immigrants, holding age constant, there is a double benefit from arriving in the U.S. at younger age. Not only is the person more efficient at acquiring language skills but also they are subject to greater exposure to the English language through more years spent in the U.S. after immigration (Shields and Price, 2002). While workers with higher education possess relatively greater initial ELP, older experienced workers are less fluent than their counterparts. For the Mexican immigrants, the negativity of the estimated coefficients for the two location variables, "California," and "Texas" imply that Mexican workers residing in these states are less likely to be proficient in English language. This result confirms the theoretical conjectures given by Lazear (1995) and McManus (1989). However, the same is not true for Chinese immigrants. In particular, the positive and statistically significant estimated coefficient of the location variable "Texas" is an unexpected result and requires more explanation. Although incomplete, the best conjecture at this time is that relatively better-educated Chinese workers who have advanced ELP reside in Texas.

To investigate the effects of ELP on earnings, we estimate the empirical specification (2). For the ELP variables, the omitted category is assigned to the respondents who speak English "Very well," and "Speaks only English." 
(2) $\ln W A G E=\beta_{0}+\beta_{1} \operatorname{Exp}+\beta_{2} \operatorname{Exp}^{2}+\beta_{3} Y s m+\beta_{4} Y_{s m^{2}}+\beta_{5} E d u+\beta_{6}$ Married $+\beta_{7}$ South +

$$
\begin{aligned}
& \beta_{8} E L P 2+\beta_{9} E L P 3+\beta_{10} E L P 4+\beta_{11} E L P 2 * H s+\beta_{12} E L P 3 * H s+\beta_{13} E L P 4 * H s+ \\
& \beta_{14} E L P 2 * \text { College }+\beta_{15} E L P 2 * \text { College }+\beta_{16} E L P 3 * \text { College }+v
\end{aligned}
$$

The first column in Table 3 lists the estimated coefficients of the earnings equation for the pooled sample. Almost all the estimated coefficients are statistically significant at 5 percent level, confirm the theoretical implications, and are consistent with the findings of the existing works. Estimated coefficients for "Experience," and "Years since migration" variables show the concave trends of the impact of these variables on the earnings. Educational attainment is found to positively influence the earnings, as does the marital status.

The negative sign of the variable "Being Mexican" shows that Mexican immigrants earn 6.42 percent less than comparable Chinese immigrants. ${ }^{10}$ Six variables for the interaction relationships between ELP and educational attainment are considered. If the estimated coefficients of the variable "ELP2" that are interacted with "College" are negative, the language status of a worker being categorized as ELP2 will decrease the college educated worker's earnings in comparison with workers who are also college educated, and speak English "very well."

\begin{tabular}{|c|c|c|c|}
\hline Variables & Pooled Sample & Chinese immigrants & Mexican immigrants \\
\hline $\begin{array}{l}\text { Exp }^{2} \\
\text { Exp }^{2} \\
\text { Ysm } \\
\text { Ysm } 2 \\
\text { Edu } \\
\text { Married } \\
\text { South } \\
\text { Being Mexican } \\
\text { ELP2 } \\
\text { ELP3 } \\
\text { ELP4 } \\
\text { ELP2 x Hs } \\
\text { ELP3 x Hs } \\
\text { ELP4 x Hs } \\
\text { ELP2 x College } \\
\text { ELP3 x College } \\
\text { ELP4 x College } \\
\text { Constant } \\
\text { Adjusted R } \\
\text { \# Of Observations }\end{array}$ & $\begin{array}{l}.0128 *(.0011) \\
-.0198 *(.0017) \\
0254 *(.0090) \\
-.0004 *(.0001) \\
.0309 *(.0009) \\
.1154 *(.0056) \\
-.1592 *(.0057) \\
-.0642 *(.0083) \\
-.0356 *(.0082) \\
-.1426 *(.0077) \\
-.2057 *(.0094) \\
-.0825 *(.0108) \\
-.1395 *(.0120) \\
-.1767 *(.0205) \\
.1671 *(.0198) \\
-.1258 *(.0301) \\
-.0573(.0652) \\
1.4437(.0200) \\
.1784 \\
62,091\end{array}$ & $\begin{array}{l}.0066 *(.0028) \\
-.0108 *(.0048) \\
.0251 *(.0024) \\
.0003 *(.0001) \\
.0516 *(.0029) \\
.0914 *(.0218) \\
-.0709 *(.0231) \\
\\
-.2663 *(.0459) \\
-.3908 *(.0357) \\
-.4845 *(.0416) \\
-.0655(.0449) \\
-.1769 *(.0335) \\
-.2677 *(.0524) \\
.2089 *(.0507) \\
-.1427 *(.0556) \\
-.0516(.1285) \\
1.447 *(.0576) \\
.3897 \\
7,580\end{array}$ & $\begin{array}{l}.0099 *(.0011) \\
-.0141 *(.0017) \\
.0247 *(.0010) \\
-.0004 *(.0001) \\
.0235 *(.0090) \\
.1224 *(.0057) \\
-.1736 *(.0057) \\
\\
-.0173 *(.0082) \\
-.1210 *(.0077) \\
-.1842 *(.0095) \\
-.0365 *(.0113) \\
-.0681 *(.0132) \\
-.0827 *(.0226) \\
-.0066(.0331) \\
-.0487(.0411) \\
.0096(.0773) \\
1.453 *(.0177) \\
.1329 \\
54,511\end{array}$ \\
\hline
\end{tabular}

Table 3: Estimated coefficient of the earnings regression (standard errors in parentheses)

To look into the different pattern of the impact of explanatory variables on the earnings of Chinese and Mexican immigrants, we estimated the earnings equation separately. The results are listed in the second and third columns in the Table 3. The Chow test of equality between the two sets of estimated coefficients between Chinese and Mexican immigrants' earnings equations is highly significant with F statistics of 58.9, thereby rejecting the null hypothesis of equivalent coefficients to justify the use of separate earnings equations for the two groups. Again, almost all the estimated coefficients are statistically significant at 5 percent level and are consistent with the theoretical implications. 
The signs and magnitudes of the ELP variables confirm our theoretical prediction that workers with lower ELP are penalized in the labor market, and provide quantitative measures how the pattern differs between Chinese and Mexican immigrants. For Chinese immigrants, in comparison with the omitted group of the workers who speak English "very well," workers with less than high school education who speak English "well" earns 26.6 percent less, while workers with less than high school education who speak English "not well," and workers with less than high school education who speak English "not at all," make 39.1 and 48.5 percent less than the omitted group. Although Mexican immigrants display similar qualitative patterns, the quantitative pattern is quite different. For Mexican immigrants with less than high school education, in comparison with the omitted group of the workers who speak English "very well," workers who speak English "well" earns only 1.7 percent less, while workers who speak English "not well," and workers who speak English "not at all," make 12.1 and 18.4 percent less.

While it is strongly confirmed that better ELP directly influences immigrants for all educational categories and for both Chinese and Mexican immigrants, the labor market penalty for the lack of ELP is most severe for the workers with high school education and not for the workers with college education as was expected. One conjecture is that those workers with college education may be able to compensate for the lack of ELP with their skills that are valued in the U.S. labor market. Using the workers with ELP1 "very well" as a baseline, we compare the labor market penalty for the lack of ELP among three categories of educational attainment as follows.

Table 4: The labor market penalty for the lack of ELP (Baseline is ELP1: speak English very well)

\begin{tabular}{|c|c|c|c|c|c|c|}
\hline & \multicolumn{3}{|c|}{ Chinese immigrants } & \multicolumn{3}{|c|}{ Mexican immigrants } \\
\hline & Below HS & $\mathrm{HS}$ & College & Below HS & $\mathrm{HS}$ & College \\
\hline $\begin{array}{l}\text { ELP2 (Well) } \\
\text { ELP3 (Not well) } \\
\text { ELP4 (Not at all) }\end{array}$ & $\begin{array}{l}-26.6 \% * \\
-39.1 \% \\
-48.5 \%\end{array}$ & $\begin{array}{l}-33.1 \% \\
-56.8 \% * * \\
-74 \%-\end{array}$ & $\begin{array}{r}-6 \% \\
-32 \% \\
54 \%\end{array}$ & $\begin{array}{r}-1.7 \% \\
12.1 \% \\
-18.4 \%\end{array}$ & $\begin{array}{l}-6 \% \\
-19 \% \\
-26 \%\end{array}$ & $\begin{array}{r}-4 \% \\
-16 \% \\
-17 \%\end{array}$ \\
\hline
\end{tabular}

* In the second column of the Table 3, the estimated coefficient for the variable "ELP2" of Chinese immigrants is -.2663. This measures the percentage of the earnings loss that occurs to the workers with less than high school education and in the ELP2 category compared to the workers with same educational attainment and in the ELP1 category.

** In the second column of the Table 3, the estimated coefficient for the variable "ELP3" of Chinese immigrants is -.3908 and the estimated coefficient for the interaction variable "ELP3*Hs" is -.1769 . The sum of these numbers, -.5677 or approximately 56.8 percent measures the earnings loss that occurs to the workers with high school education and in the ELP3 category compared to the workers with same educational attainment and in ELP 1 category.

As both groups of immigrants are almost identical in the length of residence in the U.S., the role of "Ysm" variable does not play a meaningful role to explain this rather surprising pattern. One conjecture is that there is a possibility that Chinese immigrants and Mexican immigrants engage in different types of occupations. Since the Chinese immigrants are better educated and have higher ELP than Mexican immigrants, it is likely that Chinese immigrants have professional or managerial types of occupations that require a smooth communication skill. Therefore, the lack of ELP penalizes the workers without it a lot more severely in Chinese sample. This result can be applied to explain the different patterns of the impact of educational attainment on earnings. As Chinese immigrants are relatively better educated, and consequently are believed to have better jobs that value the marketable skills obtained from higher education, marginal impact of an additional year of schooling is higher for Chinese immigrants than Mexican immigrants.

The empirical results imply that finding ways to address the educational needs of Mexican workers should be a high priority. The fact that Mexican workers exhibit lower educational attainment than Chinese workers suggests that a lack of ELP may be an important deterrent to educational success (Bleakley and Chin, 2002; Little and Triest, 2002). Given the reciprocal relationship between educational attainment of immigrant workers and their 
ELP, the improved ELP by public policies will induce greater educational attainment and vice versa and consequently enhance earnings power in the labor market. Bellante and Kogut (1998) succinctly described this situation as "win-win situation" in which educational attainment and earnings will be enhanced with an improvement of ELP (Bellante and Kogut, 1998).

The lower ELP combined with lower educational attainment of immigrants, Mexican immigrants in particular, may hamper their successful educational careers and employment outcomes. Given the pervasiveness of this problem and the differences that was found, for example between Mexican immigrants and Chinese immigrants, concerted efforts should be exerted to improve the ELP of immigrants. Although arrival at early age facilitates the acquisition of ELP, the residence in the ethnic enclave will provide counteractive forces in the ELP acquisition endeavor. Continuing residence in the ethnic enclave will probably prevents immigrant children from acquiring adequate ELP, and the lack of it will be perpetuated into their future career, encountering difficult time to advance to higher education. The rate of not completing high school is the highest among immigrants with limited ELP. Given that Mexican population is the largest and one of the fastest growing group with lower ELP, public policy attention should be focused on the Mexican immigrant youth.

\section{Summary and conclusions}

Using 1990 Census PUMS data, this paper analyzes the determinants of ELP and its effects on the earnings of Chinese and Mexican male immigrants in the U.S. The empirical results show that ELP plays an important role to explain the earnings gap in immigrant sample, and the patterns differ between Chinese and Mexican immigrants. While the disparity in earnings will be substantially reduced for Chinese immigrants by strengthening the ELP, the role of ELP to narrow the earnings disparity across different educational categories for Mexican immigrants is not as large.

The empirical results substantiate the theoretical conjectures: higher educational attainment is strongly associated with higher earnings and the earnings losses immigrants experience due to the lack of ELP are substantial. Since the ELP is probably one of the most important and essential human capital characteristics in the U.S. labor market, the lack of it prevents immigrants, especially who received all their education in the country of origin before migrating to the U.S. at a relatively late age, from overcoming their surroundings and assimilating into the U.S. society. It also prevents them from being rewarded for the human capital they possess, possibly perpetuating the earnings gap between immigrant workers and native workers

A defining characteristic of American society is the diversity represented by the symbiotic presence of many ethnic groups along with different cultures and languages. However, the lack of proper ELP imposes a substantial penalty on workers. If foreign-born children residing in the ethnic enclaves fail to evince adequate level of ELP when they are ready to go to school, the lack of ELP will produce potentially detrimental impacts on the educational attainment, and subsequently economic performance in the future. Acquiring ELP involves both costs and expected benefits. Public policy should focus on the creation of an environment in which immigrants realize the benefits of the acquisition of ELP and that the acquisition of ELP is not an option in the U.S. labor market

Concerns about linguistic assimilation is understandable but should not be exaggerated. It is unlikely that immigrant workers fail to improve ELP because they do not know the benefits of it, or the U.S. government did not impose the official use of English language. In line with Espenshade and Fu (1997), the empirical results obtained in this paper lead us to be optimistic about the linguistic assimilation of immigrants. As immigrants stay longer in the U.S., their ELP was shown to improve and their ELP will be further enhanced with additional educational attainment. The findings of Gonzalez (2002) shed a light about the concerns. Gonzalez (2002) found that once the immigrants attain ELP in several skills, further ELP does not yield substantial increase in earnings. Also found was that immigrants still continued to acquire reading skills after 20 years in the U.S. These findings altogether suggest that immigrants may learn English not for economic reasons but for social reasons, perhaps to assimilate socially into the U.S. society, and therefore immigrants do not need to be forced to acquire ELP through legislation.

Encouragement rather than enforcement is a possible policy instrument. Government may find it worth- 
while to invest into such programs as English-as-a-Second-Language (ESL) to enhance language skills of immigrants (Gonzalez, 2002). Implementation of language program such as ESL depends on the marginal cost and marginal social benefits from the program. It is therefore most important to obtain reliable estimates of the costs and benefits (Dustmann and Fabbri, 2000). In the similar vein, recent proposal to refuse public education to undocumented children may end up being counterproductive (Espinosa and Massey, 1997). As the empirical evidence clearly shows, educational attainment strongly enhances the ELP, which will most likely be translated into higher earnings in the labor market and less frequent use of welfare benefits.

\section{Endnotes}

1. According to Chiswick (1978), the speed of this process for white immigrants was fast enough to generate economic parity with the comparable native workers within 15 years. However, Borjas (1985) criticized this claim by arguing that Chiswick's view of immigrants' economic assimilation is the result of the confusion between assimilation effect and cohort effect. Borjas further argued that immigrants quality have been deteriorated substantially, and cast a doubt on the immigrants' ability to assimilate economically.

2. Recent analyses for the U.S., Canada, Australia, Israel, and Germany show that fluency and literacy in the dominant language in host country are important components for explaining immigrants' labor market success (Dustmann and Fabbri, 2000).

3. Among the population older than 5 and over in 2000 who spoke a language other than English at home, 59.9 percent spoke Spanish, up from 54.4 percent in 1990. Spanish was the most frequently spoken foreign language, followed by French or Creole, German, Chinese, and Italian. A total of 4.5 million Americans spoke an Asian or Pacific Island language. In some states, the percentages of those speaking a language other than English at home were significantly higher than the national average - 36 percent in New Mexico, 31 percent in California, and 20 percent each in Arizona, Hawaii, New Jersey, New York, and Texas (http://www.diversityrx.org/HTML/ESLANG.htm).

4. Existing research on the determinants of U.S. immigrants' ELP suffers from "disciplinary balkanization," with an attention being focused on Spanish-speaking male immigrants to the relative exclusion of other immigrant groups (Espenshade and Fu, 1997). Therefore, investigation of the other dominant group is appropriate.

5. For example, some 42 percent of Hispanics lived in predominantly Hispanic neighborhoods in 1990 (Chiswick and Miller, 1999).

6. Immigrants from Taiwan and Hong Kong are excluded. To avoid the confounding effects of ancestry and place of birth, samples include individuals of Chinese ancestry who were born in China, and individuals of Mexican ancestry who were born in Mexico.

7. Most important is the computation of work experience. Due to the intermittent labor force participation behavior of female workers, women's work experience computed by the conventional formula "Age Years of Schooling -6 " is known to be unreliable.

8. Although self-assessment of language ability always poses various problems for accuracy, there are no other data that provide a large number of observations for immigration research.

9. For the ordered probit analysis, ELP is reordered as whole numbers from 1 for "not at all" to 4 for "very well."

10. Table 1 shows that Chinese immigrants earn approximately 40 percent more than Mexican immigrants. A conjecture was that a major portion of the difference is due to the disparity of educational attainment. However, why the Mexican immigrants earn 6.42 percent less than the comparable Chinese immigrants, ceteris paribus, is uncertain at this point.

11. Dustmann and van Soest (2002), using panel information to assess the effects of language proficiency on earnings among immigrants in Europe, found that negative biases from random measurement errors from language misclassification overshadowed positive biases from errors due to unobserved fixed effects.

\section{References}

1. Bellante, Don and Carl Kogut. 1998. "Language Ability, U.S. Labor Market Experience and the Earnings of Immigrants." International Journal of Manpower 19(5), pp. 319-27. 
2. Bleakley, Hoyt and Aimee Chin. 2002. "Language Skills and Earnings: Evidence From First-Generation Immigrants." Mimeograph.

3. Borjas, George. 1994a. "Assimilation and Changes in Cohort Quality Revisited: What happened to Immigrant Earnings in the 1980s?" Working Paper No. 4866, National Bureau of Economic Research, September, Cambridge, MA.

4. Borjas, George. 1985. "Assimilation, Changes in Cohort Quality, and the Earnings of Immigrants." Journal of Labor Economics 3, pp. 463-89.

5. Chiswick, Barry. 1978. "The Effects of Americanization on the Earnings of Foreign-Born Men." Journal of Political Economy 86, pp. 897-921.

6. Chiswick, Barry. 1991. "Speaking, Reading, and Earnings of Low-Skilled Immigrants." Journal of Labor Economics 9, pp. 149-70.

7. Chiswick, Barry and Paul Miller. 1995. "The Endogeneity Between Language and Earnings: International Analysis.” Journal of Labor Economics 13, pp. 245-87.

8. Chiswick, Barry and Paul Miller. 1999. "Language Skills and Earnings Among Legalized Aliens.” Journal of Population Economics 12(1), pp. 63-89.

9. Dávila, Alberto and Marie Mora. 2001. "Hispanic Ethnicity, English-Skill Investment, and Earnings.” Industrial Relations 40(1), pp. 83-8.

10. Dustmann, Christian and Arthur Van Soest. 2002. "Language and the Earnings of Immigrants." Industrial and Labor Relations Review 55(3), pp. 473-92.

11. Dustmann, Christian and Francesca Fabbri. 2000. "Language Proficiency and Labour Market Performance of Immigrants in the UK." IZA Discussion Paper No. 156.

12. Espenshade, Thomas, and Haishan Fu. 1997. "An analysis of English-Language Proficiency Among U.S. Immigrants.” American Sociological Review 62, pp. 288-305.

13. Espinosa, Kristin and Douglas Massey. 1997. "Determinants of English Proficiency among Mexican Migrants to the United States.” International Migration Review 31(1), pp. 28-50.

14. Genier, Gilles. 1984. "The Effects of Language Characteristics on the Wages of Hispanic-American Males." The Journal of Human Resources 19(1), pp. 35-52.

15. Gonzalez, Arturo. 2000. "The Acquisition and Labor Market Value of Four English Skills: New Evidence From NALS." Contemporary Economic Policy 18(3), pp.259-69.

16. Lazear, Edward. 1995. "Culture and Language.” NBER Working Paper No. 5249

17. Little, Jane Sneddon and Robert Triest. 2002. "The Impact of Demographic Change on U.S. Labor Markets." New England Economic Review (First Quarter), Federal Reserve Bank of Boston, pp. 47-68.

18. McManus, Walter. 1989. "Labor Market Effects of Language Enclaves: Hispanic Men in the United States." Journal of Human Resources 25(2), pp. 228-52.

19. McManus, Walter. 1985. "Labor Market Costs of Language Disparity: An Interpretation of Hispanic Earnings Differences." American Economic Review 75, pp. 818-27.

20. Mosisa, Abraham. 2002. "The Role of Foreign-born Workers in the U.S. Economy." Monthly Labor Review (May), pp. 3-14.

21. Park, Jin Heum. 1999. "The Earnings of Immigrants in the United States: The Effect of English-Speaking Ability." The American Journal of Economics and Sociology 58(1), pp. 43-57.

22. Shiedls, Michael and Wheatley Price. 2002. "The English Language Fluency and Occupational Success of Ethnic Minority Immigrant Men Living in English Metropolitan Areas.” Journal of Population Economics 15, pp. 137-61. 